\title{
Studies on Stigmatella aurantiaca (Myxobacterales)
}

\author{
By H. REICHENBACH* AND M. DWORKIN \\ University of Minnesota, Department of Microbiology, \\ Minneapolis, Minnesota 55455, U.S.A.
}

(Accepted for publication 6 May 1969)

\section{SUMMARY}

We have isolated the fruiting myxobacterium Stigmatella aurantiaca from wood and bark, and have examined some aspects of its ecology, morphology, physiology and taxonomy. Vegetative cells were Gram-negative, spindle-shaped rods 5.2 to $8.4 \mu$ long and 0.65 to $0.74 \mu$ wide. The myxospores were optically refractile short rods measuring about $3.2 \times \mathrm{I} \cdot 0 \mu$. Fruiting bodies were usually bright orange or red brown and consisted of a stalk 60 to $140 \mu$ high bearing I to 20 cysts at its top. Most cysts were spherical or ovoid, measuring 40 to $60 \mu$ by 25 to $45 \mu$. S. aurantiaca was cultivated in liquid culture in a dispersed vegetative state or on solid media, producing either fruiting bodies or vegetative forms. Optimal vegetative growth was obtained with a medium containing Casitone, glucose and salts. The optimal temperature for growth was $30^{\circ}$. Cultures could be preserved by storage of vegetative forms at $-60^{\circ}$ or of dried myxospores or fruiting bodies at $-18^{\circ}$. Dried myxospores were resistant to desiccation and elevated temperatures. We propose that Stigmatella, which had been incorporated into the genus Chondromyces, be re-established as a separate genus within the Polyangiaceae. We further propose the inclusion of Chondromyces among the Sorangiaceae.

\section{INTRODUCTION}

When Thaxter in 1892 recognized Stigmatella aurantiaca (Chondromyces aurantiacus) as a myxobacterium, it had already been described three times as a member of the fungi imperfecti (Berkeley, I857; Berkeley \& Broome, I873; Kalchbrenner \& Cooke, 1880). Thaxter said: 'With the exception of Myxococcus rubescens this is the commonest member of the group [i.e. myxobacteria] and must have been met with by anyone who has sought for Myxomycetes on decaying wood, where though very minute it is conspicuous from its bright colour'. It would be a mistake, however, to conclude from this that $S$. aurantiaca is now a familiar or well-characterized member of the fruiting myxobacteria. European workers only rarely encountered $S$. aurantiaca (Quehl, I906; Zukal, I897) and Krzemieniewska \& Krzemieniewski wrote (I946): 'During a period of about I 5 years we were not once able to observe it' (i.e. C. aurantiacus). They finally obtained it from rotting beech wood and pine twigs.

When, in the I940s, the myxobacteria once again became the subject of investigations in North America, the organism no longer appeared to be abundant there either. The contradiction was eventually resolved by Nellis (I962), who confirmed Thaxter's observation that Stigmatella aurantiaca could easily be obtained when rotting wood was used for its isolation rather than the soil and dung used by most of the later

* Present address: Botanical Institute of the University, Department of Microbiology, 78 Freiburg, West Germany. 
investigators. Our results support these findings. When we isolated and cultivated $S$. aurantiaca and became familiar with its properties, it appeared that this organism could not be closely related to Chondromyces crocatus and $C$. apiculatus with which it had been united in one genus. The purposes of the present report are to document this statement, and to expand the existing description of $S$. aurantiaca (Solntseva, 1942).

\section{METHODS}

Media. Stock cultures were grown on $\mathrm{C} / \mathrm{IO}$ agar: Casitone (Difco), $0.3 \% ; \mathrm{CaCl}_{2}$, $9 \mathrm{~mm}$; agar (Difco), I.5\% (w/v); or on yeast agar: baker's yeast, I.0 \% (fresh weight of yeast cake); $\mathrm{CaCl}_{2}, 9 \mathrm{~mm}$; agar, $\mathrm{I} \cdot 5 \%(\mathrm{w} / \mathrm{v})$. Water agar contained agar, $\mathrm{I} \cdot 5 \%$ $(\mathrm{w} / \mathrm{v}) ; \mathrm{CaCl}_{2}, 9 \mathrm{~mm}$. Liquid cultures were kept in modified CT medium containing Casitone, $\mathrm{I} \cdot 0 \% \mathrm{MgSO}_{4}, \mathrm{IO} \mathrm{mm}$ added aseptically after autoclaving. When sugars were included, these were autoclaved separately. Liquid media for testing different $\mathrm{N}$-sources always included $10 \mathrm{mM}-\mathrm{MgSO}_{4}$. Sarcina lutea was cultivated on yeastextract agar containing Casitone, $0.3 \%$; yeast extract (Difco), $0.5 \%$; agar, I.5\% $(\mathrm{w} / \mathrm{v})$. All agar media were adjusted to $\mathrm{pH} 7 \cdot 2$ with $\mathrm{KOH}$. The liquid media were usually used at their original value of $\mathrm{pH} 6.8$; when $\mathrm{N}$-sources other than Casitone were used, the media were adjusted to $\mathrm{pH} 7 \cdot 0$. Soft agar for pour plates was $\mathrm{C} / \mathrm{Io}$ agar but with $0.5 \%$ agar.

Cultivation. All cultures were kept at $30^{\circ}$ : the plate cultures in a dark incubator at high humidity, the liquid cultures on a reciprocal water-bath shaker (I 20 strokes/min.). Liquid cultures were grown either in $250 \mathrm{ml}$. conical flasks or in nephelometer flasks, both containing $25 \mathrm{ml}$. medium/flask. Growth was determined by measuring extinction in a Klett-Summerson colorimeter at $540 \mathrm{~nm}$. The results obtained with this method were sometimes misleading, e.g. when the organisms lysed because of unfavourable conditions, producing a dark pigment. In doubtful cases the cultures were examined with the microscope, and, when necessary, growth was determined by counting organisms in a Petroff-Hausser chamber.

Experimental methods. For freeze-drying, organisms were suspended in skim milk, put into ampoules, shell frozen, and dried in high vacuum.

Determination of the $\mathrm{pH}$ optimum of growth was made in liquid medium with

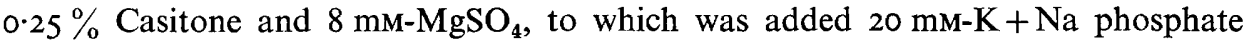
buffer at different $\mathrm{pH}$ values. To keep the concentration of monovalent cations constant, compensatory amounts of $\mathrm{NaCl}$ were added. $\mathrm{NaCl}$ alone at $20 \mathrm{~mm}$ had no pronounced influence on growth.

Resistance to ultrasonic treatment was tested by treating $5 \mathrm{ml}$. batches in a MSE ultrasonic vibrator at maximal energy output (about $20 \mathrm{kcyc}$.); the samples were kept in an ice bath during treatment. When treatment for several minutes was required, this was done intermittently to avoid heating. Decrease of number of organisms was examined by counting in a Petroff-Hausser chamber.

Heat resistance was determined by heating samples in a water bath. To allow rapid temperature equilibration, only 0.2 to $0.5 \mathrm{ml}$. amounts of suspensions were used, and they were put into preheated tubes. The heated organisms were streaked on C/Io agar. To test heat resistance of dry myxospores, $0.2 \mathrm{ml}$. samples of a spore suspension in modified CT medium were put in sterile tubes and dried in high vacuum for $10 \mathrm{hr}$; the spores formed a thin film on the bottom of the tube so that rapid heat transfer was guaranteed. After heating, $0.5 \mathrm{ml}$. of sterile water was added, and the resuspended 
myxospores streaked on C/IO agar. These experiments were only roughly quantitative, i.e. survival was judged from growth delay and amount of growth, as compared with controls.

\section{RESULTS AND DISCUSSION}

\section{Isolation and ecology}

Rotting soft wood (Salix, Populus, Acer) and bark from fallen trees were collected during the summer and autumn months in and around Minneapolis, Minnesota. The specimens were put into large Petri dishes lined with filter paper, and were moistened with distilled water so that they were wet but not soaked. The crude cultures were incubated at $30^{\circ}$ and examined daily with a dissecting microscope for fruiting bodies. When these appeared at all they always did so during the first few days of incubation. Stigmatella aurantiaca appeared quite regularly, usually forming 10 to 100 fruiting bodies on one piece of wood. It was often accompanied by Chondromyces or other less conspicuous myxobacteria.

Occasionally fruiting bodies were observed in nature. In one instance a large log showed bright orange patches consisting of tens of thousands of fruiting bodies of Stigmatella aurantiaca. Nellis (1962) pointed out that $S$. aurantiaca could easily be isolated from specimens which were completely dry upon collection. We found that pieces of wood with fruiting bodies could be stored dry in the laboratory for more than I year, and the organism readily isolated when the wood was moistened and incubated for I to 2 days. Stigmatella aurantiaca seems to live primarily in the surface layers of the decaying material; samples taken from the interior of rotting trunks did not yield cultures.

For isolation, fruiting bodies were transferred to streaks of living Sarcina lutea on water agar. After incubation for I to 2 days at $30^{\circ}$, small swarms had developed, which lysed the sarcinas rapidly. From the edge of these swarms transfers were made to fresh bacterial streaks. A few passages eliminated amoebae, nematodes and fungi. Invariably, however, bacterial contaminants remained within the slime layers of the swarm, in close association with the myxobacteria, as also described for Chondromyces species (Abadie, I966). The contaminants were usually small non-motile rods carried along with the myxobacterial cells; they were found throughout the swarm, even at the rapidly migrating edge. Pure cultures of Stigmatella aurantiaca were obtained by three different methods. (I) Swarm material taken from C/Io agar was suspended in $0.3 \%$ Casitone in a screw-cap tube and shaken vigorously with glass beads $(0.5$ to $\mathrm{I} \cdot 0 \mathrm{~mm}$.), the supernatant fluid diluted appropriately, mixed with molten soft agar and poured as a thin layer on top of a C/IO agar base. This technique is a modification of one described by McCurdy (1963). (2) Fruiting bodies, which were readily formed on streaks of $S$. lutea or when swarm material was transferred from $\mathrm{C} / \mathrm{IO}$ agar to water agar, were exposed to ultrasonic treatment for 2 to $3 \mathrm{~min}$. A relatively uniform suspension of myxospores was then obtained which could be plated as above. The ultrasonic treatment also killed many of the contaminating organisms. (3) Fruiting bodies were suspended in sterile distilled water, heated in a water bath at $57^{\circ}$ for 15 to $20 \mathrm{~min}$. and then transferred to C/Io agar. While myxospores survived the heat treatment, the contaminants were usually all killed (Solntseva, 1939). From several pure strains, one clone, croCl I, obtained by method I, was chosen for detailed study. 
In our experience Stigmatella aurantiaca did not appear in cultures prepared from dung or soil, which yielded a variety of other closely related myxobacteria. Other investigators have reported similar results (Krzemieniewska \& Krzemieniewski, I946; Nellis, 1962). Though $S$. aurantiaca has been found in soil and on dung (Agnihothrudu, Barua \& Barua, I959; Krzemieniewska \& Krzemieniewski, I927; Krzemieniewska \& Krzemieniewski, 1930; Nellis, 1962; Solntseva, 1942) it seems to prefer rotting wood or bark as a habitat; at least it can be obtained from these sources much more readily. The basis for this preference is not clear, especially since our physiological studies with pure strains have shown that $S$. aurantiaca is very similar in its requirements and properties to Podangium erectum and Polyangium fuscum, both of which are quite commonly isolated from soil and dung. Like the other fruiting myxobacteria, S. aurantiaca can be cultivated easily on $\mathrm{C} / \mathrm{I} O \mathrm{O}$ agar or yeast agar; it readily forms fruiting bodies on these agars, is strongly bacteriolytic, and does not produce cellulases.

\section{Cellular morphology}

The vegetative forms of Stigmatella aurantiaca are spindle-shaped rods, $5 \cdot 2$ to $8 \cdot 4 \mu$ long and 0.65 to $0.74 \mu$ wide (Pl. I, fig. I). Their shape is different from that of the cylindrical blunt-ended vegetative rods of Chondromyces crocatus (Pl. I, fig. 2), and a Sorangium sp. (Pl. I, fig. 3). They resemble the vegetative forms of Podangium and the somewhat longer and more slender forms of Podangium.

Vegetative forms of Stigmatella aurantiaca readily formed spheroplasts, e.g. in old liquid cultures, or when suspended in $\mathrm{CsCl}$ solution (above Io $\mathrm{mm}$ ). We did not purify the $\mathrm{CsCl}$ used and its toxicity may have been due to contaminating materials. In contrast to Myxococcus xanthus (Mason \& Powelson, 1958), S. aurantiaca did not form spheroplasts on exposure to Io $\mathrm{mM}-\mathrm{Na}^{+}$or $\mathrm{K}^{+}$.

The myxospores of Stigmatella aurantiaca were optically refractile short rods, often slightly bent, with rounded ends (Pl. I, fig. 4, 5). In this respect as well, it differs from Chondromyces and Sorangium species, where the rods within fruiting body cysts appear very similar to the vegetative forms. Myxospores from fruiting bodies of $S$. aurantiaca measured about $3.2 \times \mathrm{I} \cdot 0 \mu(2.6$ to $3.5 \times 0.9$ to $\mathrm{I} \cdot 2 \mu)$ but were occasionally even shorter and fatter. They are surrounded by a thin capsule as shown by electron microscopy (Reichenbach, Voelz \& Dworkin, I969), whereas the myxospores of Chondromyces are not encapsulated (McCurdy, 1967). The fine structure of vegetative forms and myxospores of $S$. aurantiaca has been described elsewhere (Reichenbach et al. 1969).

\section{Fruiting-body structure}

Fruiting bodies of Stigmatella aurantiaca consisted of a stalk 60 to I $40 \mu$ high and bearing I to 20 cysts at its top (Pl. 2, fig. 6). The fruiting body was 130 to $200 \mu$ high. The cluster of cysts had a diameter of $\mathrm{I} 20$ to $220 \mu$.

The stalk, whose width ranged between 35 and $100 \mu$, usually broadened considerably toward its base. Sometimes it formed a narrow board-like ridge rather than a tapering column (Pl. 2, fig. 7). It was only rarely branched, but often several stalks arose from a common base. The stalk consisted largely of hardened slime, in which some cells were always embedded. It was sometimes unpigmented and opaque, but was often yellowish or brownish. Occasionally, rudimentary fruiting bodies bearing only a single cyst were formed (P1. 2, fig. 8). 
The cysts were spherical, ovoid, pear-shaped or subcylindrical, and usually narrowed at the base into a white slime pedicel about 1o $\mu$ wide and Io to $20 \mu$ long, or sometimes longer. Occasionally, no pedicel was developed. The dimensions of the cysts varied from 25 to $102 \times 16$ to $70 \mu$; most cysts measured 40 to $60 \times 25$ to $45 \mu$. The fruiting bodies were usually bright orange or red brown, but the pigmentation varied from light yellow-brown to dark chestnut-brown or almost black. This variability in cyst size and colour was observed with the same strain even under apparently identical culture conditions.

The cyst was surrounded by a tough wall which had an irregularly wrinkled surface. All the pigment seemed to be contained in this wall. The myxospores inside the cyst were embedded in a slimy matrix and not arranged in any specific pattern. Electronmicroscope observations on the fruiting body structure of Stigmatella aurantiaca will be published later (Voelz \& Reichenbach, in preparation).

\section{Swarm structure}

The swarm of Stigmatella aurantiaca is typical for the Podangium-Polyangium group. It developed an irregular edge (PI. 2, fig. 9) and lacked a pronounced marginal ridge. The swarm showed well-developed radial streams and often a pattern of oscillating waves which were originally thought to be typical for the Myxococcaceae (Reichenbach, 1965). Although the majority of cells were concentrated in the marginal area, the central parts of the swarm, especially along the radial streams, remained densely populated even at late stages of swarm development. The cells deposited a tough slime layer, but the surface of the agar was only slightly changed. The swarm sometimes appeared unpigmented; however, when the cells were concentrated, a pink pigmentation was visible. On $\mathrm{C} / \mathrm{I}$ o agar older swarms were often light to dark brown, and on yeast agar, yellow or yellow brown.

The swarms of Chondromyces and Sorangium species are quite different (Reichenbach, Kuczka \& Heunert, I964). There the vegetative cells concentrate at the relatively smooth swarm edge often forming a heavy ridge, which may be bright yellow or orange. These swarms, at least in their central parts, are usually sunk into the agar forming a shallow pit, with the cells generally penetrating into the substrate. There is no tough slime layer, but the agar surface is heavily etched, deep holes and trenches often being produced by the activity of the cells.

\section{Cultivation and growth requirements}

Stigmatella aurantiaca grew quite well on two of the standard media for myxobacteria (C/IO agar, yeast agar) though fruiting bodies were not formed on either substrate. Fruiting bodies were readily obtained when swarm material was transferred to a streak of living Sarcina lutea on water agar. When these cultures were incubated at $30^{\circ}$, the early stages of fruiting-body formation were observed after Io to $15 \mathrm{hr}$ and mature fruiting bodies were present after $24 \mathrm{hr}$. The sarcinas as well as the yeast cells in yeast agar were lysed by the myxobacterium, producing large clear zones.

Stigmatella aurantiaca also grew in liquid CT medium shaken at $30^{\circ}$. In the initial cultures most of the population grew in clumps, but after a few passages growth occurred as an even suspension. This was true of all three strains tested, though the number of passages required to yield dispersed growth differed. Once a strain showing dispersed growth was established, it could also grow in static liquid culture and 
still form a uniform suspension. Such strains showed a completely different swarm morphology when transferred back to agar plates from a liquid culture; the cells spread only slowly over the substrate, the swarms appeared soft and slimy, without the typical surface pattern, and no fruiting bodies were formed when transfers were made to water agar. Even after many transfers from plate to plate, reversion to the original type was not observed.

Suspension cultures of strains which give dispersed growth were used to study the nutritional requirements of Stigmatella aurantiaca in more detail. Optimal growth was obtained with a medium containing: I \% Casitone, $30 \mathrm{~mm}$-glucose or $20 \mathrm{~mm}-$ sucrose, I2.5 mM- $\mathrm{MgSO}_{4}$, Io mM- $\mathrm{PO}_{4}$ buffer $(\mathrm{pH} 7 \cdot 2)$. Omission of sugar and phosphate resulted in a relatively small decrease in growth. The generation time at $30^{\circ}$ was 7 to $8 \mathrm{hr}$ for both variants of the medium. In unbuffered sugar-free Casitone medium the $\mathrm{pH}$ was shifted during growth from $6 \cdot 8$ to $7 \cdot 8$. Soon after the stationary phase was reached, the cells lysed and the culture became black within I to $2 \mathrm{hr}$. When sugars were present, the $\mathrm{pH}$ decreased to 5.8 to $6 \cdot 2$, and the culture in stationary phase remained brownish or became bright ochre. At this stage the cells usually converted to myxospores, presumably because of the acid produced. Induction of myxospore formation will be described in a subsequent paper (Reichenbach \& Dworkin, in preparation).

Growth of Stigmatella aurantiaca required a complex N-source which was best provided by enzymic hydrolysates of protein, e.g. Casitone. The optimal concentration was I $\%$. At $2 \%(\mathrm{w} / \mathrm{v})$, as used in CT medium for Myxococcus xanthus (Dworkin, 1962), growth was inhibited and there was a sharp decrease below $0.5 \%$ (Fig. I). Compared with Casitone under the same conditions, much less growth was obtained with Tryptone (Difco) or vitamin-free Casitone (Difco), and no growth at all with Casamino acids (Difco) or L-asparagine (20 mM with I5 mM-sucrose). Addition of $30 \mathrm{~mm}$ glucose or $20 \mathrm{mM}$-sucrose to Casitone medium resulted in higher population densities and a decrease from $\mathrm{pH} 7 \cdot 0$ to $\mathrm{pH} 5.8$ to 6.2 in the culture during growth. This effect was unexpected, as growth of $M$. xanthus was not improved by sugars (Dworkin, 1962), nor could we find any response to glucose with a variety of strains of Myxococcus fulvus, $M$. virescens, $M$. xanthus, Chondrococcus coralloides and C. macrosporus.

When glucose was added to Casitone medium before sterilization growth was markedly inhibited, as compared with cultures containing either separately autoclaved glucose or without glucose. However, there was still considerable development, and the $\mathrm{pH}$ value became almost as low as in the control with separately sterilized glucose, indicating that some glucose was metabolized.

As with other myxobacteria, growth of Stigmatella aurantiaca depends on the presence of divalent cations in fairly high concentrations. In plate cultures $\mathrm{Ca}^{2+}$ fulfilled this requirement. In liquid suspension cultures, however, only $\mathrm{Mg}^{2+}$ was used, since $\mathrm{Ca}^{2+}$ caused the cells to clump and settle on the glass walls of the flask. The optimal concentration of $\mathrm{Mg}^{2+}$ in I \% Casitone medium was about $12.5 \mathrm{~mm}$ (Fig. I).

It was not necessary to add phosphate to the Casitone medium, since Casitone contains sufficient phosphate; $\mathrm{pH} 7 \cdot 0$ to 7.2 was optimum for growth; there was no growth at $\mathrm{pH} 6.4$ and a marked decrease at $\mathrm{pH} 6.6$; there was still good growth at pH 7.6 (Fig. I).

The optimal temperature for growth was about $30^{\circ}$; some growth was possible at a temperature as high as $37^{\circ}$. 
The poor growth of Stigmatella aurantiaca in vitamin-free Casitone suggested a requirement for growth factors. However, growth was not improved by addition of yeast extract, mixtures of water-soluble vitamins or of trace elements. It is possible that the vitamin-free Casitone used contained a growth inhibitory substance.

\section{Preservation of cultures}

Vegetative swarms of Stigmatella aurantiaca on C/Io agar or yeast agar usually lost viability after 2 to 3 weeks of incubation at $30^{\circ}$. Liquid cultures in the absence of acid production lysed after 3 to 4 days. A convenient method for preserving myxobacterial cultures was accordingly sought. Storage of cultures at $4^{\circ}$ was not effective even though growth and swarming ceased. When fruiting bodies were formed, however, successful transfers could be made from cultures kept for 14 months at $4^{\circ}$.

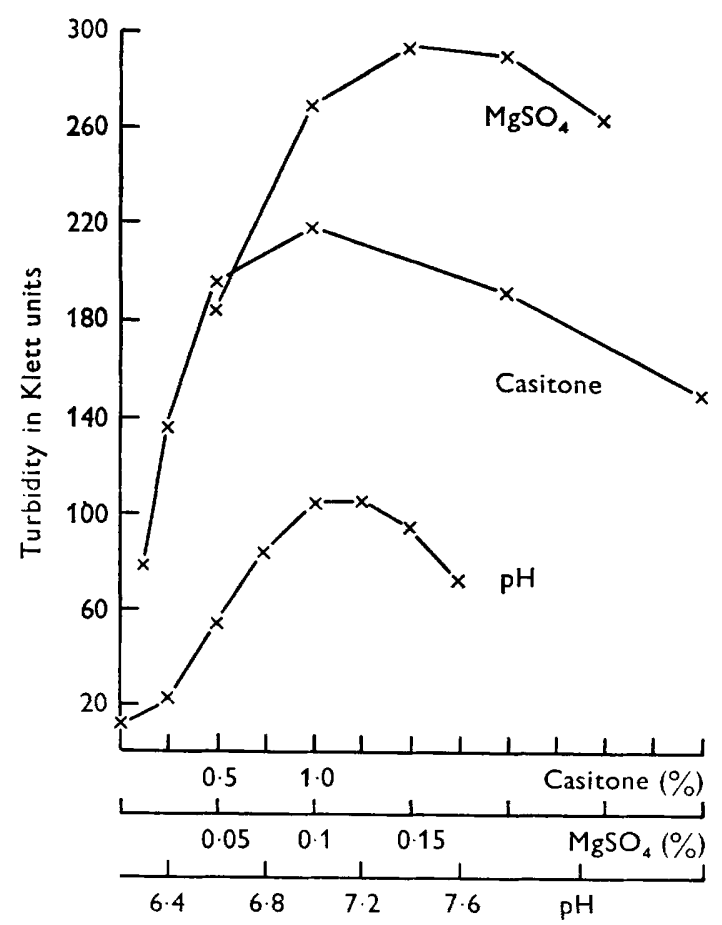

Fig. I. Growth response of Stigmatella aurantiaca suspension cultures to different pH values and concentrations of Casitone and $\mathrm{MgSO}_{4}$. Growth was determined turbidimetrically after incubation for $55 \mathrm{hr}$. Media: (a) different concentrations of Casitone $+0.1 \% \mathrm{MgSO}_{4}$, pH 6.8; (b) $1 \%$ Casitone + various concentrations of $\mathrm{MgSO}_{4}, \mathrm{pH} \mathrm{6.8;} \mathrm{(c)} 0.25 \%$ Casitone $+0.1 \% \mathrm{MgSO}_{4}+0.02 \mathrm{M}$-phosphate buffer at various $\mathrm{pH}$ values.

Excellent results were obtained with freezing. Samples $(2 \mathrm{ml}$.), from liquid cultures in the exponential phase of growth, were placed in screw-cap tubes, frozen immediately in solid $\mathrm{CO}_{2}+$ acetone and stored at $-60^{\circ}$. These cultures were thawed at room temperature and inoculated into liquid medium; within $24 \mathrm{hr}$ dense cultures had usually arisen. The organism remained viable in the frozen state for at least 12 months. It was important, however, that the suspension be frozen rapidly and stored at very 
low temperatures; cells thawed after a few days at $-20^{\circ}$ invariably lysed. Freezing was also used to store slope agar cultures. Swarms on $\mathrm{C} /$ Io agar slopes quick-frozen and stored at $-60^{\circ}$ were still viable after $\mathrm{I} 8$ months. The freezing and thawing process caused the agar to become quite soft, but the swarm sheet remained intact and could easily be removed. It should be emphasized that both freezing techniques are effective for the preservation of most myxobacteria, e.g. Myxococcus, Chondrococcus, Polyangium and Podangium species, with the notable exception of Chondromyces apiculatus (the only Chondromyces species tested) and Sorangium species. Chondromyces apiculatus swarms (four strains) barely survived a few months in the frozen state while Sorangium swarms were always killed by freezing and thawing unless fruiting bodies were present. Freeze-drying was unreliable for the preservation of Stigmatella aurantiaca as well as for other fruiting myxobacteria.

The most convenient and effective method for the preservation of Stigmatella aurantiaca or fruiting myxobacteria in general was the storage of dry myxospores or fruiting bodies. A dense suspension of myxospores dropped on small pieces of filter paper in a Petri dish was dried in a desiccator. (Myxospores of $S$. aurantiaca could be obtained by the glycerol technique devised for Myxococcus xanthus; Dworkin \& Gibson, 1964). The dried specimens were placed in screw-cap tubes and stored at room temperature or in a freezer. Myxospores thus kept at $-18^{\circ}$ were viable after 17 months.

Fruiting bodies could be grown directly on filter paper; pieces of filter paper (about $25 \times 15 \mathrm{~mm}$ ) were laid on water agar and inoculated heavily with swarm material from a growth culture. Within $24 \mathrm{hr}$ fruiting bodies were formed, which were then allowed to mature for 3 to 5 days. The filter-paper strips were placed in screw-cap tubes and dried in vacuo. Such fruiting bodies were still viable after 20 months at room temperature.

\section{Resistance properties of myxospores}

Vegetative forms of Stigmatella aurantiaca were very sensitive to ultrasonic treatment. Starting with $4.5 \times 10^{8}$ cells $/ \mathrm{ml}$, less than $\mathrm{I} \%$ remained viable after treatment for $30 \mathrm{sec}$. When myxospores were treated under comparable conditions, $70 \%$ remained viable after I min., $30 \%$ after $3 \mathrm{~min}$. and $5 \%$ after $6 \mathrm{~min}$.

Vegetative forms of Stigmatella aurantiaca were quickly killed upon drying, even under careful conditions of freeze-drying. Myxospores, on the other hand, were completely resistant to drying. A similar situation exists with Myxococcus xanthus (Sudo \& Dworkin, 1969). Myxospores can be stored in the dry state for months without losing their capacity to germinate when moistened. It seems likely that the resistance to drying is an important biological function of myxospores, for myxobacteria are frequently in environments which periodically become dry. Heating a suspension of $S$. aurantiaca myxospores at $5 \mathrm{I}^{\circ}$ for $\mathrm{I} 5 \mathrm{~min}$. killed all the myxospores; however, when they were heated in the dry state they easily withstood temperatures of $6 \mathrm{I}^{\circ}$ and $68^{\circ}$ for $\mathrm{I} 5 \mathrm{~min}$., and were killed slowly at $74^{\circ}$ and $83^{\circ}$; a few myxospores even survived $15 \mathrm{~min}$. at $90^{\circ}$. A similar difference in heat resistance between dry and wet spores was shown for Myxococcus fulvus (Baur, I905). Thus, it is clear that dry myxospores are easily capable of withstanding any temperatures they may be exposed to in their natural environment.

\section{Fruiting-body formation}

Fruiting-body formation by Stigmatella aurantiaca could be induced by transferring swarm material from growth-supporting agar media, e.g. C/IO agar or yeast agar, to 
water agar or to filter paper placed on water agar. When such plates were incubated at $30^{\circ}$, the differentiation of cysts had begun by $15 \mathrm{hr}$. The cysts were intially translucent, but soon became pigmented and opaque; at about $24 \mathrm{hr}$ the fruiting bodies appeared to be mature.

It was not possible to maintain ability to form fruiting bodies in a culture which had been repeatedly grown and transferred on rich media which prevented fruiting. This loss of fruiting ability by a culture which had been maintained on rich media is an unexplained phenomenon common among the myxobacteria.

\section{Taxonomy}

Stigmatella aurantiaca is presently included in the genus Chondromyces as Chondromyces aurantiacus. Stigmatella aurantiaca differs from Chondromyces crocatus, the type species of the genus, in the shape of the vegetative cells, in the way myxospores are formed (in Chondromyces there is either no visible difference between vegetative cells and myxospores, or at most a slight shrinkage), in swarm morphology, and even in some characteristic features of the otherwise quite similar fruiting bodies. We therefore propose that these two organisms be classified in separate genera.

The genera Stigmatella and Chondromyces were proposed by Berkeley (I857), for organisms which he assumed to be fungi imperfecti; the original descriptions consisted only of the line drawings of the type species, Stigmatella aurantiaca and Chondromyces crocatus. These drawings as well as a later description (Berkeley, I874) were based on specimens collected by P. Ravenel in South Carolina, U.S.A., and kept in the Curtis herbarium. Berkeley also described $S$. aurantiaca a second time as a new species of Hyphomycetes, Stilbum rhytidosporum (Berkeley \& Broome, 1873). A third description of the same organism came from Kalchbrenner \& Cooke (I880), who presented it as a new species and a new genus, Polycephalum aurantiacum, believed to be closely related to the fungal genus Stilbum.

Stigmatella aurantiaca was recognized as a myxobacterium by Thaxter (I 892), who also realized that this organism was identical with the various 'fungi imperfecti' mentioned above. The identity was later confirmed by Massee (1893), who examined the original material on which the various descriptions were based.

Thaxter united the genera Chondromyces and Stigmatella, eliminating the name Stigmatella which had been published after Chondromyces. This merger was based entirely on the similarity of the fruiting bodies of both organisms. Thaxter incorrectly described the vegetative cells of $C$. crocatus as 'cylindrical or tapering slightly' (I 892). The fact that there are two rather different cell types among myxobacteria was realized only much later by Krzemieniewska \& Krzemieniewski (1928). They also called attention to the similarity between the vegetative cells of Chondromyces crocatus and Sorangium and to the fact that Stigmatella aurantiaca cells are different from both, though their statement that 'such cells [as in C. crocatus] are not to be found in any other Chondromyces species' (I946) is not correct.

If the genus Chondromyces is split, the original generic name of Stigmatella once again becomes valid. It is unlikely that this would cause any nomenclatural confusion as the generic name was used only once again, i.e. by Saccardo (I886), for Sphaerocreas pubescens = Stigmatella pubescens, an unjustified synonomy which was subsequently rejected by Thaxter (I892). There are some fungal genera with similar names, as 
Stigmatea Mont., Stigmea Fr., Stigmella Lev., and Stigmatula Sacc., but these names are sufficiently different from Stigmatella to exclude confusion.

The genus Stigmatella may then be redefined as: myxobacteria with vegetative cells which have tapering ends, and which change considerably in shape during myxospore formation; myxospores short fat rods, optically refractile, with a thin capsule; fruiting bodies consist of a slime stalk (which is not branched and does not exceed 200 to $300 \mu$ in length), bearing a cluster of cysts at its top; cysts with a tough cyst wall. Type species: Stigmatella aurantiaca Berk. \& Curt. I857.

The genus Chondromyces comprises: myxobacteria with vegetative cells which have blunt, rounded ends, of the Sorangium type; they change little in size and shape during myxospore formation; myxospores look like vegetative cells (have no capsule); fruiting bodies with slime stalks ( $500 \mu$ or more long, with longitudinal streaks), branched or unbranched, with clusters of cysts at the top; cysts with tough cyst wall. Type species: Chondromyces crocatus Berk. \& Curt. I857. (Characters given in parentheses have still to be examined with more strains and species before their taxonomic weight can be validated). Three other species which undoubtedly belong to the genus Stigmatella have been named, namely $C$. brunneus (Krzemieniewska \& Krzemieniewski, 1946), $C$. cylindricus (Krzemieniewska \& Krzemieniewski, 1930), and C. medius (Krzemieniewska \& Krzemieniewski, 1930). These three species are supposed to differ from Stigmatella aurantiaca in shape, size, and colour of their cysts. However, in the light of the variability we found with our strains, we believe that the above mentioned species can be regarded at best as varieties of $S$. aurantiaca.

Stigmatella aurantiaca is closely related to Podangium erectum as realized by both Thaxter (I897) and the Krzemieniewskis (1927). Actually, S. aurantiaca sometimes produces atypical fruiting bodies with single cysts on top of the cystophore (Pl. 2, fig. 8). These can hardly be distinguished from fruiting bodies of $P$. erectum. Thus, locating the genus Stigmatella within the family Polyangiaceae has a sound basis. Within this family, the genus Stigmatella has the most complex fruiting bodies and marks the end of a continuous morphological sequence which begins with the unstalked cysts of Polyangium fuscum. The genus Chondromyces on the other hand may be justifiably transferred into the family Sorangiaceae, for the genera Chondromyces and Sorangium have much in common: both share the same type of vegetative cells; in both, myxospores do not differ morphologically from vegetative rods; both have a similar growth pattern, with swarms sinking into the agar to form shallow pits with pronounced marginal ridges. Even the pigmentation is often the same-a bright yellow orange which is unusual among the myxobacteria. The similarity in fruiting-body structure between the genera Stigmatella and Chondromyces can probably be regarded as a result of evolutionary convergence.

We are grateful to Dr H. McCurdy for strains of Chondromyces crocatus. This work was supported by U.S. Public Health Service Grant AI-08036 from the National Institute of Allergy and Infectious Diseases. H. Reichenbach thanks the German Research Association for a travel grant to the United States. M. Dworkin is a Research Career Development Awardee of the National Institute of General Medical Sciences, National Institutes of Health, GM-05869. 


\section{REFERENCES}

ABADIE, M. (1966). Sur une eubactérie liée au cycle vital d'une myxobactérie: Chondromyces crocatus (Berkeley et Curtis). C.r. hebd. Séanc. Acad. Sci., Paris, D 263, 736.

Agnihothrudu, V., Barua, G. C. S. \& Barua, K. C. (I959). Occurrence of Chondromyces in the rhizosphere of plants. Indian Phytopath. 12, I 58.

BaUR, E. (1905). Myxobakterien-Studien. Arch. Protistenk. 5, 92.

Berkeley, M. J. (1857). Introduction to Cryptogamic Botany. pp. 313, 315. London.

BERKELEY, M. J. (1874). Notices of North American fungi. Grevillea 3, 64, 97.

Berkeley, M. J. \& Broome, C. E. (1873). Enumeration of the fungi of Ceylon. J. Linn. Soc. (Bot.) 14, 96.

DworkIn, M. (I962). Nutritional requirements for vegetative growth of Myxococcus xanthus. J. Bact. 84, 250.

Dworkin, M. \& Gibson, S. M. (1964). A system for studying microbial morphogenesis: Rapid formation of microcysts in Myxococcus xanthus. Science, N.Y. 146, 243.

Kalchbrenner, C. \& CoOKe, M. C. (I880). South African fungi. Grevillea 9, 22.

KrzemiteniewsKa, H. \& Krzemieniewski, S. (1927). Die Myxobakterien von Polen. Anhang. Acta Soc. Bot. Pol. 4, 79.

Krzemieniewska, H. \& Krzemieniewski, S. (I928). Zur Morphologie der Myxobakterienzelle. Acta Soc. Bot. Pol. 5, 46.

Krzemieniewska, H. \& Krzemieniewski, S. (1930). Die Myxobakterien von Polen. III. Teil. Acta Soc. Bot. Pol. 7, 250.

Krzemieniewska, H. \& Krzemieniewski, S. (1946). Myxobacteria of the species Chondromyces Berkeley and Curtis. Bulletin de l'Académie Polonaise des Sciences et des Lettres, Classe de Sciences Mathématiques et Naturelles, Série B: Science Naturelles (I), $3 \mathrm{I}$.

Mason, D. J. \& Powelson, D. (1958). Lysis of Myxococcus xanthus, J. gen. Microbiol. 19, 65.

MASSEE, G. (I 893). Grevillea 21, I23.

MCCuRDY, H. D. (I963). A method for the isolation of myxobacteria in pure culture. Can. J. Microbiol. 9,282 .

MCCURDY, H. D. (1967). Electron microscope observations on the fruiting bodies of Chondromyces crocatus. Bact. Proc. 38.

Nellis, L. F. (1962). A taxonomic study of the genus Chondromyces. Ph.D. thesis, Purdue University U.S.A.

QueHL, A. (1906). Untersuchungen über die Myxobakterien. Zentbl. Bakt. ParasitKde (Abt. II), 16, 9.

REICHENBACH, H. (1965). Rhythmische Vorgänge bei der Schwarmentfaltung von Myxobakterien. Ber. dt. bot. Ges. 78, 102.

Reichendach, H., KuczKa, H. \& Heunert, H. H. (1964). Chondromyces apiculatus (Myxobacteriales) - Schwarmentwicklung und Morphogenese. Encyclopaedia Cinematographica E 779. Inst. Wissensch. Film, Göttingen, Germany.

Reichenbach, H., Voelz, H. \& Dworkin, M. (1969). Structural changes in Stigmatella aurantiaca during myxospore induction. J. Bact. 97, 905.

SaCCARDo, P. A. (1886). Sphaerocreas. Sylloge Fung. 4, 679.

SOLNTSEVA, L. I. (1939). Methods of cultivation of myxobacteria. Mikrobiologiya 8, 959. (in Russian).

SolntSeVA, L. I. (1942). The biology of myxobacteria. II. The genera Melittangium and Chondromyces. Mikrobiologiya 10, 505. (in Russian).

Sudo, S. \& Dworkin, M. (I969). Resistance of vegetative cells and microcysts of Myxococcus xanthus. J. Bact. (in the Press).

ThaXTer, R. (I 892). On the Myxobacteriaceae, a new order of Schizomycetes. Bot. Gaz. 17, 389.

THAXTER, R. (I897). Further observations on the Myxobacteriaceae. Bot. Gaz. 23, 395.

ZuKaL, H. (1897). Uber die Myxobacterien. Ber. dt. bot. Ges. 15, 542. 


\section{EXPLANATION OF PLATES}

Plate I

Fig. I. Vegetative cells of Stigmatella aurantiaca. Living cells, in situ on agar surface in moist chamber. Several dividing cells can be seen. The flexibility of the rods is evident. Total magnification $\times 2800$. Phase-contrast. Zeiss microscope.

Fig. 2. Vegetative cells of Chondromyces crocatus. Living cells, in situ on agar surface in moist chamber. Total magnification $\times 2$ I90. Phase-contrast. Zeiss microscope.

Fig. 3. Vegetative cells of a cellulose-decomposing Sorangium strain. Living cells, in situ on agar surface in moist chamber. Total magnification $\times 1820$. Phase-contrast. Zeiss microscope.

Fig. 4. Myxospores of Stigmatella aurantiaca. Living cells, formed on agar surface in moist chamber, in situ. Total magnification $\times 2750$. Phase-contrast. Zeiss microscope.

Fig. 5. Myxospores of Stigmatella aurantiaca. Living cells on agar surface in moist chamber, in situ. With the $\times 40$ objective the high optical refractility of the myxospores becomes apparent. Optical refractility is not obvious in fig. 4 , which was taken with a $\times 100$ oil-immersion objective. Total magnification $\times$ I 125 . Phase-contrast. Zeiss microscope.

\section{Plate 2}

Fig. 6. Fruiting body Stigmatella aurantiaca. On agar surface. Pure culture. Total magnification $\times 340$. Zeiss microscope.

Fig. 7. Atypical fruiting body of Stigmatella aurantiaca. With a flat board-like stalk. On agar surface. Pure culture. Total magnification $\times 200$. Zeiss microscope.

Fig. 8. Rudimentary fruiting body of Stigmatella aurantiaca. With one single cyst on top of slime stalk. On agar surface. Pure culture. Total magnification $\times 420$. Zeiss microscope.

Fig. 9. Stigmatella aurantiaca, swarm edge. Pure culture grown on plain water agar. Total magnification $\times 95$. Zeiss microscope. 
Journal of General Microbiology, Vol. 58, No. I

Plate I
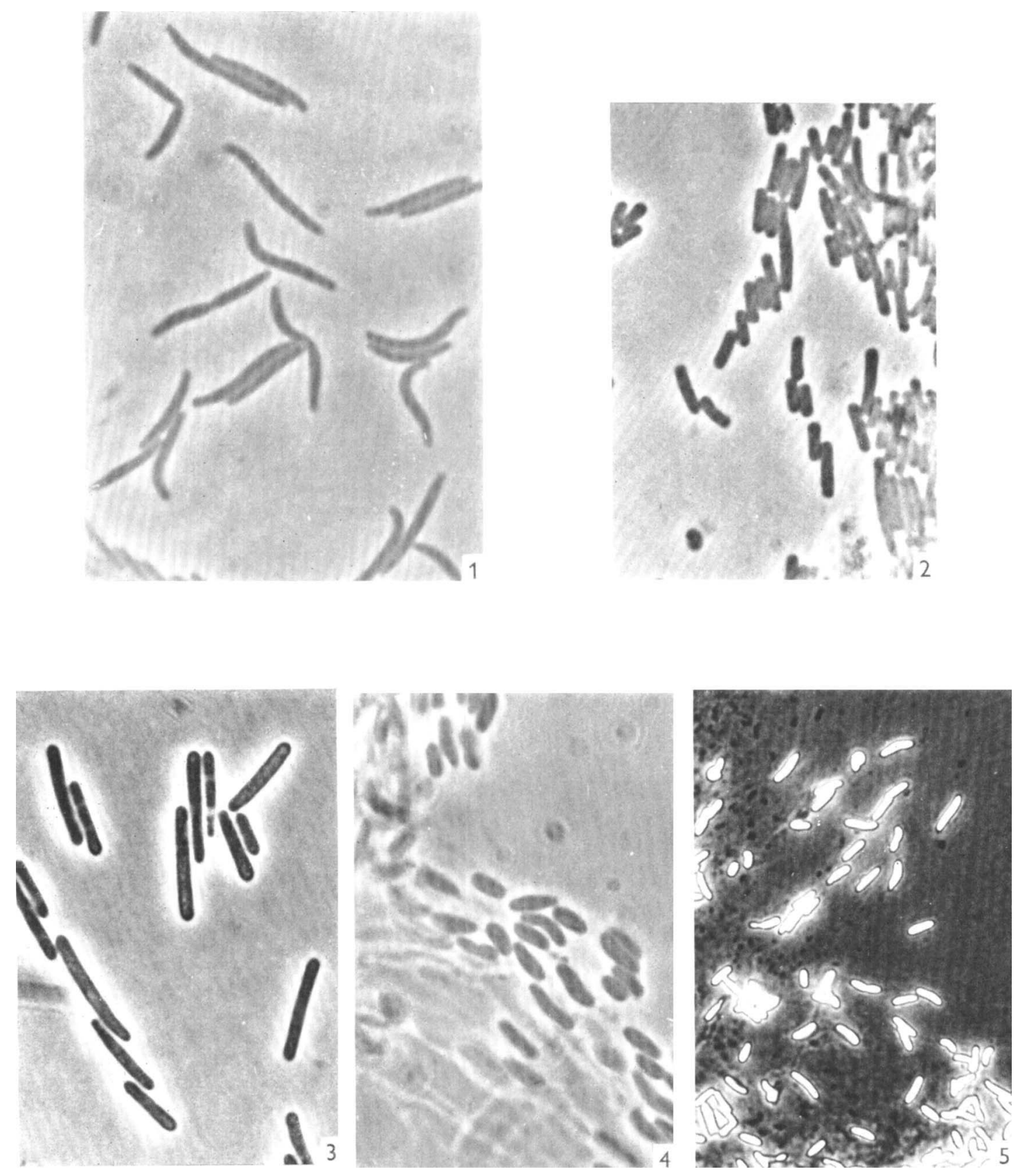

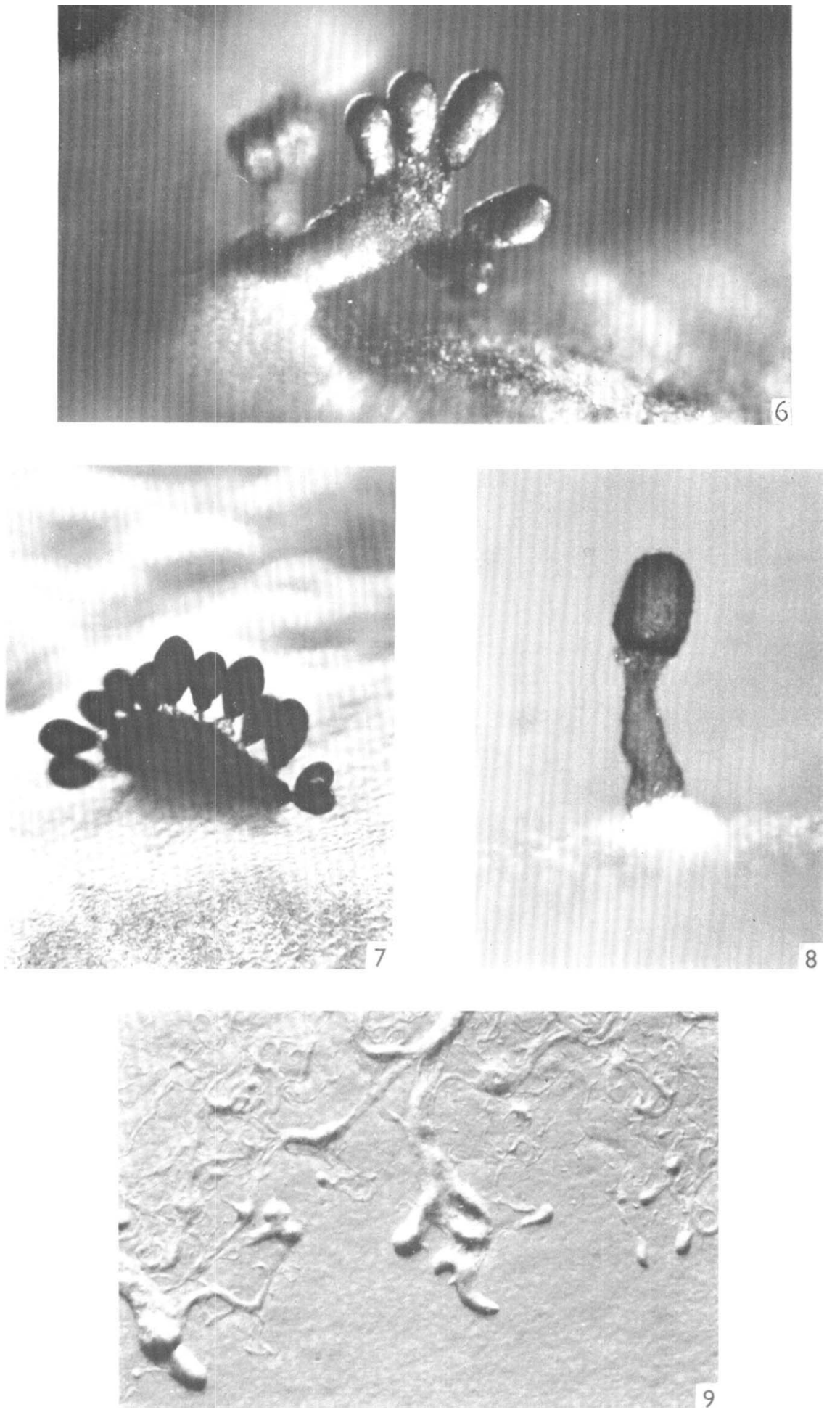